Article

\title{
Case Study of an Automatic Enrichment Device for Laying Hens on a Free-Range Laying Hen Farm
}

\author{
Melanie Schmidt, Jenny Stracke, Katja Kulke, Nicole Kemper *(D) and Birgit Spindler
}

Institute for Animal Hygiene, Animal Welfare and Farm Animal Behavior, University of Veterinary Medicine Hannover, Foundation, Bischofsholer Damm 15, D-30173 Hannover, Germany; melanie.schmidt@tiho-hannover.de (M.S.); jenny.stracke@tiho-hannover.de (J.S.);

katja.kulke@tiho-hannover.de (K.K.); birgit.spindler@tiho-hannover.de (B.S.)

* Correspondence: nicole.kemper@tiho-hannover.de; Tel.: +49-511-856-8951

Received: 14 March 2019; Accepted: 25 April 2019; Published: 1 May 2019

\begin{abstract}
Access to adequate foraging material can reduce the occurrence of feather pecking and cannibalism in laying hens. Technical devices may help farmers provide enrichment material more effectively. However, research in this field is rare. On a commercial free-range farm with 15,000 laying hens (Lohmann Tradition), an enrichment device was evaluated from the 30th to the 58th week of age (LW). It ran at five time points (TP) in the afternoon and offered five grams of dried maize silage per hen per day. The numbers of hens residing in defined scratching areas (ScA) either beneath the device (ScA 1 and 3) or in a similar area without the device (ScA 2) were determined. Significantly more hens were found in ScA 1 and ScA 3 when the device was running. On average, only $6.96( \pm 7.00)$ hens stayed in ScA 2, whereas $31.45( \pm 5.38)$ and $33.83( \pm 6.16)$ hens stayed in ScA 1 and ScA 3, respectively. The hen numbers for ScA 1 and ScA 3 did not differ significantly, nor did the TPs have an influence on number of hens within ScA 1 and ScA 3. The number of hens beneath the device can serve as a potential indicator of the device's usage.
\end{abstract}

Keywords: animal welfare; cannibalism; feather pecking; foraging; intact beak; technical devices; maize silage

\section{Introduction}

Feather pecking and cannibalism are still common behavioral problems in laying hen husbandry, and have been observed in all traditional European housing systems [1-5]. These behavioral disorders can cause an increased feed intake, higher rates of mortality, and lower egg production rates [3,6,7], which implies economic losses for the farmers. Furthermore, they constitute animal welfare problems, because they are stressful and painful for their victims and may result in severe injuries [8-11].

The trimming of chicks' beaks using a hot blade or infrared technology is commonly practiced worldwide to reduce the impact of feather pecking and cannibalistic behavior. Even though negative long-term effects may be reduced for different variations of this procedure (e.g., different methods or bird ages), short-term consequences such as pain, loss of beak sensibility, and altered pecking behavior have been observed [12-16]. Therefore, this practice has already been banned in many European countries (e.g., Norway, Sweden, Finland, Switzerland, and Germany) or will be so in the near future (e.g., the Netherlands, the United Kingdom) for animal welfare reasons. However, the subsequent challenge for farmers is to realize an economical but also animal-friendly husbandry to prevent the occurrence of feather pecking and cannibalism in flocks while keeping laying hens with intact beaks.

Many studies have shown that feather pecking and cannibalism are influenced by various factors (e.g., genetics, group size, diet composition or structure, and light regimens) [16-21]. The provision of suitable litter [22-26] and enrichment material [27-34] has been found to reduce feather pecking 
and cannibalism. Red jungle fowl are known to spend a large proportion of their daytime activity on ground scratching (60\%) and pecking (34\%) on forest soil (i.e., foraging) [35]. This behavior is also prominent in domestic fowl, which has been found to perform foraging in enriched as well as in unenriched conditions (roughly 38\%) [36]. Furthermore, scratching and pecking are even carried out when feed is available ad libitum via feeding bowls [36]. Therefore, foraging behavior seems to be a special need of laying hens. If such an intrinsic behavioral pattern cannot be performed, it might lead to behavioral disorders [37,38]. Even more so, preventing animals from performing such natural behaviors violates the five welfare needs as stated by Mellor [39].

Recommendation leaflets/guidelines for farmers on how to deal with feather pecking and cannibalism in laying hen husbandry include proposals of commercial available enrichment materials (e.g., pecking blocks, alfalfa hay balls, grain, silage, carrots, or potatoes), as they enable foraging behavior [40-42]. Offering enrichment material requires labor and time-intensive engagement to ensure a comprehensive and continuous supply. To enable a less laborious provision of such materials, technical devices may be used [42]. Giersberg et al. [43] tested a device offering moistened maize silage within the winter gardens of a commercial free-range farm, and stated that such devices can provide adequate enrichment, based on the revealed use and acceptance by the hens. Nevertheless, there has been a lack of research about these techniques. The aim of this case study was to evaluate the use of an automatic enrichment device and evaluate the factors potentially affecting its usage (e.g., different times of supply, the hens' age, and their placement within the stable) under on-farm conditions.

\section{Material and Methods}

\subsection{Farm, Animals, and Management}

Data collection was conducted on a laying hen farm with a free-range system in Lower Saxony, Germany. Roughly 15,000 laying hens (Lohmann Tradition, Lohmann Tierzucht GmbH, Cuxhaven, Germany) were monitored from moving in at an age of 18 weeks up to an age of 66 weeks. The stocking density was 8.7 hens per square meter.

The stable consisted of three consecutively arranged sections (Figure 1). It was divided lengthwise in four corridors by three aviary systems, each with two floors (Meller Legevoliere Model 1, MELLER International $\mathrm{GmbH}$, Melle, Germany). The hens could move freely between different corridors and aviaries within one section. The corridors served as scratching area and were littered with pellets made of lignocelluloses (ViloComfort Einstreu, ViloFoss, Neuenkirchen-Vörden, Germany). New litter was supplied at the beginning of the laying period and then according to demand. Pop holes led to a sheltered winter garden over the entire length of the right corridor. This area was also sectioned and littered with chopped straw. Wind protection meshes on the lateral surface could be moved up and down electrically to provide the hens with access to a free-range area $(60,000$ square meters) from 10:00 until 22:00. The free-range area was not sectioned, and groups of hens could mix here. An outbreak of avian influenza in the wider region required the hens to be confined, so they had no access to the free-range area from moving in until they were 30 weeks old.

When the birds moved in, day length lasted 10 hours. Within a period of six weeks, it was extended to 16 hours. Then, day length started with a dimming phase of one hour at 6:00 and ended up equally at 22:00, with a dimming phase before.

Food and water were supplied on both floors of all the aviary systems via feeding lines and nipple drinkers. The hens were fed with commercial layers of mash seven to eight times a day with block feedings in the morning and the evening. On the basis of the hens' special needs at different ages during the laying period, phase feeding with different types of feeding mash was performed. Water was offered ad libitum. Manure was removed partially once per week via manure belts within the aviary systems and via manure scrapers below the systems. 


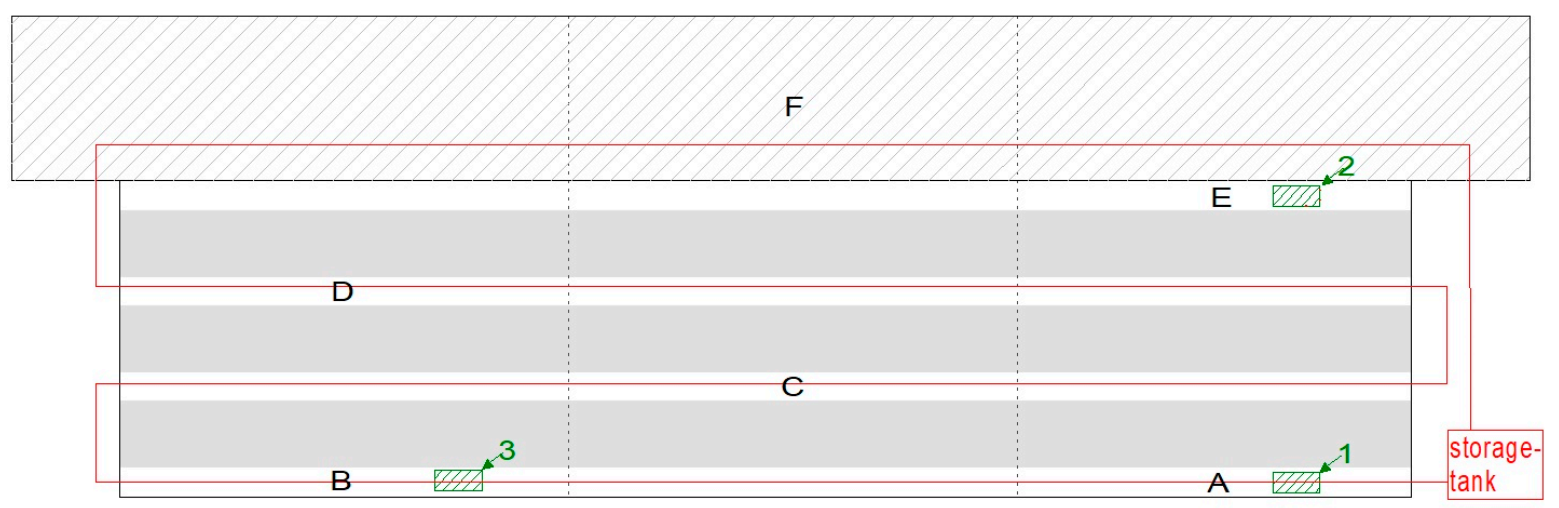

Figure 1. Top view of the stable with three aviary systems (solid grey bars) and a winter garden (hatched grey area), divided in sections (dashed lines). The automatic enrichment device (red line) led along three corridors through the stable and along the winter garden. Points for scoring $(\mathrm{A}-\mathrm{F})$ and the three fields of behavioral observations (ScA 1-3, hatched green areas) are also shown. ScA: scratching areas, ScA 1 and ScA 3: scratching areas beneath an enrichment device, ScA 2: similar scratching area without the device.

\subsection{Enrichment Materials and Device}

The commercially available automatic enrichment device (LAE-Anlagenbau $\mathrm{GmbH}$, Cuxhaven, Germany), which was installed in the stable for this study, was a self-contained system. Outside the barn, a vertical mixer with integrated scales served as a storage tank for a three-day ration of the enrichment material. From there on, a pipeline led into the stable 2.3 meters above floor level. It ran along three of the four corridors inside the pen, along the winter garden, and ended up in the mixer again (Figure 1). Within the pipeline, a chain with driving plates-which are often used in pig feeding systems-transported the material. Furthermore, a special dosing unit was interconnected within the pipeline directly after the storage tank. This unit enabled the addition of extra substances (e.g., wheat and oats, lime stone shells) to the main enrichment material, if desired. A sensor at the end of the pipeline signaled complete filling. Due to openings in the pipeline every 2.4 meters, which could be closed and opened via automatic slides simultaneously, enrichment material could trickle into the scratching area. There was a total of 92 openings ( 23 per corridor/winter garden). The amount of offered enrichment material, and the time of supply could be adjusted via a control unit. Due to local conditions and operational circumstances, dried maize silage was used as the main material.

When the birds were 29 weeks old, the device was turned on for the first time. To allow the hens to become familiarized with the device, its application was stepped up gradually. When the hens were 32 weeks old, the device provided material to the full extent. It then normally ran five times per day from the early afternoon until the evening (i.e., 13:50, 14:50, 15:50, 17:50, 19:50). This approach was selected because of the previous experiences of other farmers working with similar devices. At each time point of supply (TP), the device ran for approximately seven seconds. It spread roughly five grams of material per hen and day into the litter of the hens' scratching area. Due to deteriorations in plumage condition and the occurrence of feather pecking behavior, unprocessed grain (wheat and oats) were added to the maize silage via the special dosing unit from an age of 47 weeks and onwards, to make the material more attractive to the hens.

Besides the automatic device, other typical enrichment materials were supplied manually. One pecking block (ViloLith Pickstein, ViloFoss, Neuenkirchen-Vörden, Germany) and one alfalfa hay ball (Compact Luzerne, Hartog, Lambertschaag, the Netherlands) per corridor/winter garden and section were offered over the entire laying period and refilled as required (one per 1250 hens; 12 in total). Furthermore, baskets with potatoes were provided when hens were between 26-43 weeks old. These baskets were refilled two times per day and placed in each corridor/in the winter garden and section. 


\subsection{Behavioral Observations}

To evaluate the hens' utilization of the scratching areas and especially the influence of the enrichment device, three camera traps (SnapShot Mini, Dörr GmbH, Neu-Ulm, Germany) were installed in the stable. They took pictures for a few days every four weeks when the hens were between 30-58 weeks in age. The recording time lasted from 10:00 to 20:00 with a shooting interval of two minutes. For behavioral analyses, one day every four weeks was chosen, and we ensured that no significant disturbances (e.g., manure removal, visits from the vet, etc.) occurred on those days. Observations took place at eight times during production when the hens were 30, 34, 38, 42, 46, 50, 54, and 58 weeks of age (LW).

Based on spatial (width of corridor) and technical (camera focus and angle) possibilities and the construction of the device (distance between openings), a field of 1.0 by 2.4 meters of the scratching area was defined as observation area (ScA) for each camera (Figure 1: ScA 1-3, green rectangles). Two of the cameras were focused on an area directly beneath the device (i.e., each beneath one opening) (ScA 1 and 3). Material trickled in to the center of the observation areas. The third camera captured pictures of a comparable area in the one corridor not equipped with the device (ScA 2). The test images for all the camera traps were made using a temporary measuring frame as the camera adjustment was finished. Test images were used as a basis for further analysis.

To reveal the number of hens within the ScAs over the course of a day, one picture obtained every 10 minutes (10-minute-picture; TMP) from 10:00 until 20:00 was analyzed. A day was divided into two main parts (DT): the time before the first time of maize supply from 10:00 until 13:50 (DT 1), and the time in the afternoon during which maize silage was provided five times from 13:51 until 20:00 p.m. (DT 2). Furthermore, four time points of supply (TP: $a=13: 50, b=15: 50, c=17: 50$, and $d$ $=19: 50$ ) were selected to determine the number of hens staying in the defined ScAs after the device ran. Due to technical problems, the provision of maize at 14:50 was irregular. Therefore, this time point was excluded from the analysis. For the other TPs, pictures obtained two, four, and six minutes after the device offered enrichment material were analyzed, and a mean value was calculated for these three pictures for each observed TP per ScA and observation day. We decided to examine a period of six minutes following the findings of a previous study, in which the mean time that individual hens pecked in a circular formation around trickled material was 5:01 minutes, at the beginning of the laying period and 3:51 minutes at the end of the laying period [43]. As birds were 30 weeks old, the device only ran at 13:50 and 15:50. The camera for ScA 3 only captured images from week 38 and onwards due to a technical difficulty. Within observations on weeks 42 and 46, the device did not run at 15:50. In total, we obtained 28 observations for ScA 1 and 2 and 22 observations for ScA 3.

Virtual frames for each of the three ScAs were produced using the program GoldenRatio (Version 3.1, Markus Welz, Krailling, Germany), and test images showed the measuring frames. Every hen located within the frame with a minimum of $50 \%$ of its body (except head, neck, tail, and feet) was counted using the program ImageJ (Version 1.51q, NIH, Bethesda, Rockville, MD, USA).

\subsection{Scoring of Plumage and Integument}

To assess the condition of the flock and the stable itself, regular visits were conducted. The first visits were already carried out before the enrichment device was running and the birds were 21, 27 and 29 weeks old. From the 34th week onwards, visits were performed regularly every four weeks up to an age of 66 weeks (i.e., 12 visits in total). The scoring of plumage and integument was intended to serve as an indicator for feather pecking and cannibalism in the flock. Hens were caught, weighed, and scored in different parts of the stable (Figure 1: A-E). In total, 55 randomly chosen hens were evaluated: 10 hens on each point inside the stable (A to E), and five hens within the winter garden (F). At 21 weeks of age, the hens had no access to the winter garden. As a result, evaluation point $\mathrm{F}$ was missing, and only 50 hens were scored.

We adopted the scoring scheme of Giersberg et al. [44]. Hens received scoring notes for feather losses (FL: 0 (best) to 4 (worst)) and integument damage (ID: 0 (best) to 3 (worst)) for different sections 
of their bodies. Notes for FL were given for the head/neck, back, tail, wings, and breast/belly. The same body sections as for FL and cloaca were scored for ID. The scoring notes are explained in detail in Table 1.

Table 1. Scoring scheme for the condition of plumage and integument (Giersberg et al., 2017).

\begin{tabular}{|c|c|c|}
\hline Score/Parameter & Feather Loss (FL) & Integument Damage (ID) \\
\hline 0 & No feather loss & No integument damage \\
\hline 1 & $\leq 25 \%$ of feathers missing & Single injury $<0.5-\mathrm{cm}$ diameter or length \\
\hline 2 & $>25 \%$ and $\leq 50 \%$ of feathers missing & $\begin{array}{l}\text { Multiple injuries }<0.5-\mathrm{cm} \text { or single } \\
\text { injuries }>0.5 \mathrm{~cm} \text { and } \leq 1.0 \mathrm{~cm}\end{array}$ \\
\hline 3 & $>50 \%$ and $\leq 75 \%$ of feathers missing & Single or multiple injuries $>1.0 \mathrm{~cm}$ \\
\hline 4 & $>75 \%$ of feathers missing & - \\
\hline
\end{tabular}

\subsection{Statistical Analysis}

\subsubsection{Behavioral Observations}

All of the behavioral data were assessed using SAS Version 9.4 (SAS Institute Inc., Cary, NC, USA). The number of hens was analyzed using mixed linear models (MIXED procedure). Multiple pairwise comparisons were calculated using Tukey-Kramer tests. The level of statistical significance was set at $p<0.05$. F-value $(\mathrm{F})$ and $\mathrm{t}$-value $(\mathrm{t})$ results were also calculated.

For a general overview, first we analyzed the usage of ScAs over the course of a day. The observed scratching areas (ScA; factor with three levels: 1, 2, 3), and time of day (DT; factor with two levels: 1 and 2) and their interaction were included as fixed effects. The random effect contained the TMPs nested in LW. Second, usage within the first six minutes after the maize was supplied was analyzed, including observed scratching areas (ScA; factor with three levels: ScA 1, ScA 2, and ScA 3) and time point of the maize supply (TP; factor with four levels: a, b, c, d) as fixed factors.

For a detailed analysis of the scratching areas beneath the device, the observed scratching areas (ScA; factor with two levels: 1 and 3), the time of maize-supply (TP; factor with four levels: a, b, c, and d) and the birds' age (LW; factor with eight levels: 30, 34, 38, 42, 46, 50, 54, and 58 weeks of age) were set as fixed effects.

Furthermore, the effect of the addition of grain to the main enrichment material on the number of hens in ScA 1 and 3 during TPs was analyzed. Therefore, material (M) was defined as factor with two levels: bg (before grain, including all the observations before the 47th week of age) and ag (after grain, including all the observations after the 47th week of age) It was included in the model as a fixed factor, together with the time point of supply (TP; factor with four levels: a, b, c, and d) and scratching area (ScA; factor with two levels: 1 and 3).

\subsubsection{Scoring of Plumage and Integument}

Scoring data of FL and ID were analyzed on a descriptive basis.

\section{Results}

\subsection{Behavioral Observations}

Analysis of the mean number of hens for all three observation areas over the course of a day revealed a significant effect of both ScA and DT (ScA: F = 101.90, $p<0.001$; DT: 104.71, $p<0.001$ ). Furthermore, a significant effect of the interaction of these terms was determined $(\mathrm{F}=44.41 p<0.001)$. While ScA 2 revealed no significant difference between DT 1 and DT $2(\mathrm{t}=1.68 ; p=0.55)$, in ScA 1 and ScA 3, more hens were found for DT 2 compared with DT 1 (ScA 1: $t=-9.00 ; p<0.001$; ScA 3: $\mathrm{t}=-9.93 ; p<0.001$ ) (Figure 2).

The mixed model of the mean number of hens for all three observation areas for the first six minutes after maize supply revealed a significant effect of observation area (ScA: $\mathrm{F}=147.14 ; p<0.001$ ). 
More hens were found to be in ScA 1 and ScA 3 (equipped with the device) compared with ScA 2 (without the device) (Figure 3). On average, only $6.96( \pm 7.00)$ hens stayed in ScA 2; in contrast, $31.45( \pm 5.38)$ and $33.83( \pm 6.16)$ hens were counted in ScA 1 and ScA 3, respectively. The time of maize supply was found to have no effect on the number of hens (TP: $\mathrm{F}=0.07 ; p=0.98$ ).

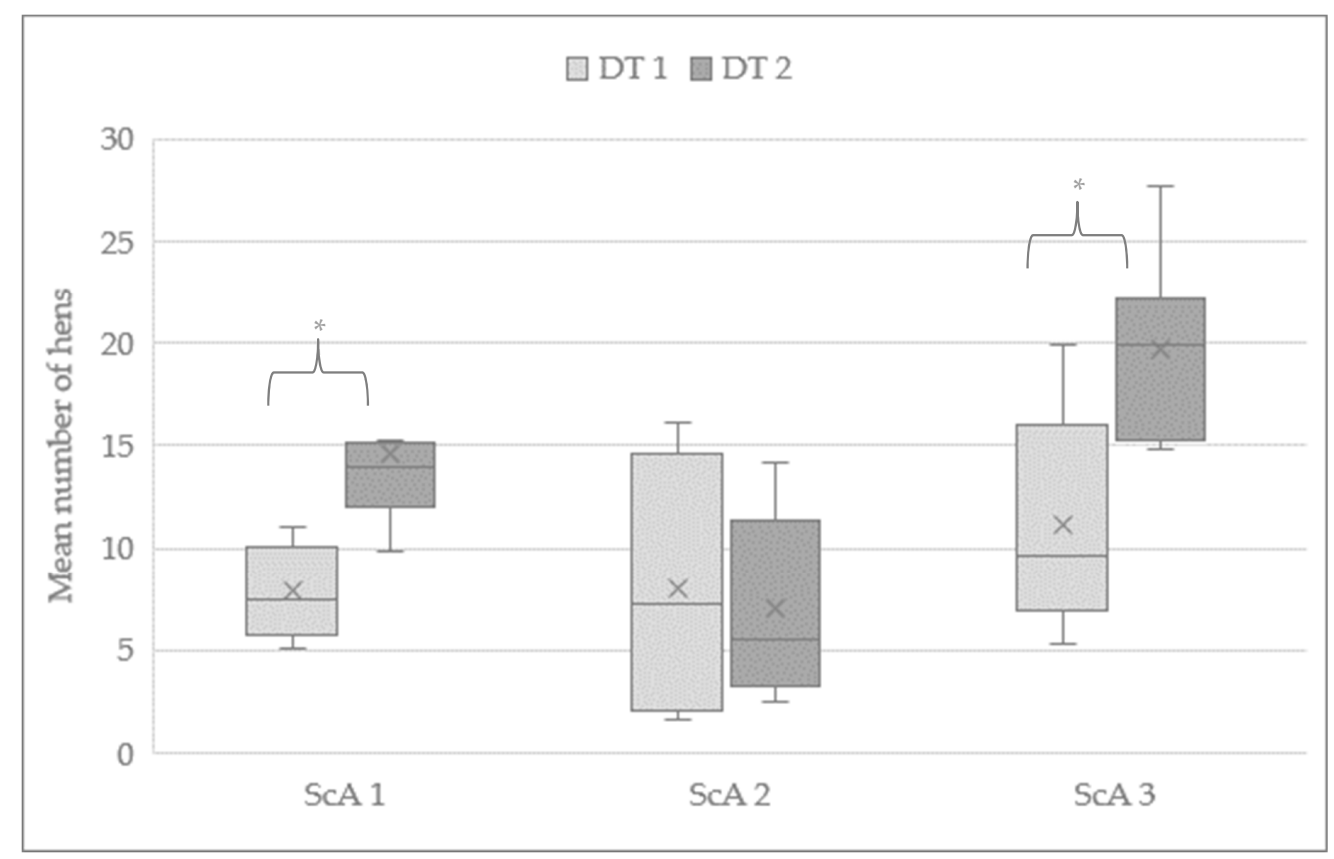

Figure 2. Mean number of hens in three different observation areas (ScA 1 and 3 with the enrichment device, and ScA 2 without the enrichment device) for different times of the day (DT 1: hours before maize supply (10:00 to 13:50); DT 2: hours during supply (13:51 to 20:00)). An asterisk indicates significant differences $(p<0.05)$. Boxplots indicate the data range, median, lower, and upper quartiles and mean value.

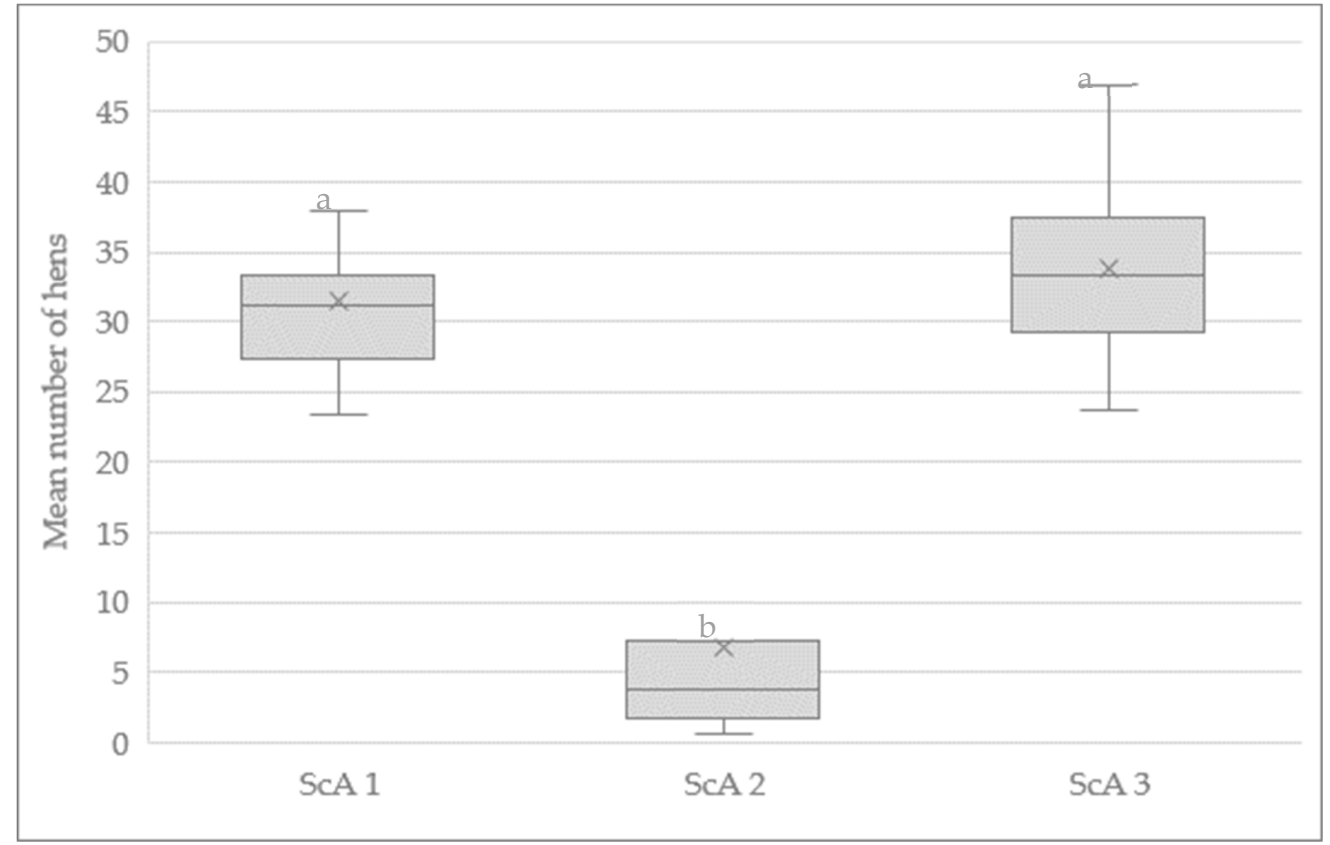

Figure 3. Mean number of hens in three different observation areas (ScA 1 and 3 with the enrichment device, and ScA 2 without the enrichment device) during the examined times of maize supply from the birds' 30th to 58th weeks of age. Different superscripts indicate significant differences $(p<0.05)$. Boxplots indicate the data range, median, lower, and upper quartiles, and mean value. 
Considering the detailed analysis of the observed scratching areas beneath the device (ScA 1 and 3), age was found to have a significant effect on the number of hens (LW: $\mathrm{F}=3.75 ; p<0.01$ ) (Figure 4). With a higher age, more hens remained in the observation area beneath the device. No difference in the number of hens between ScA 1 and ScA 3 was found (ScA: F $=1.17 ; p=0.29$ ). Time of maize supply also did not affect the number of hens (TP: $\mathrm{F}=0.23 ; p=0.88$ ) (Figure 5).

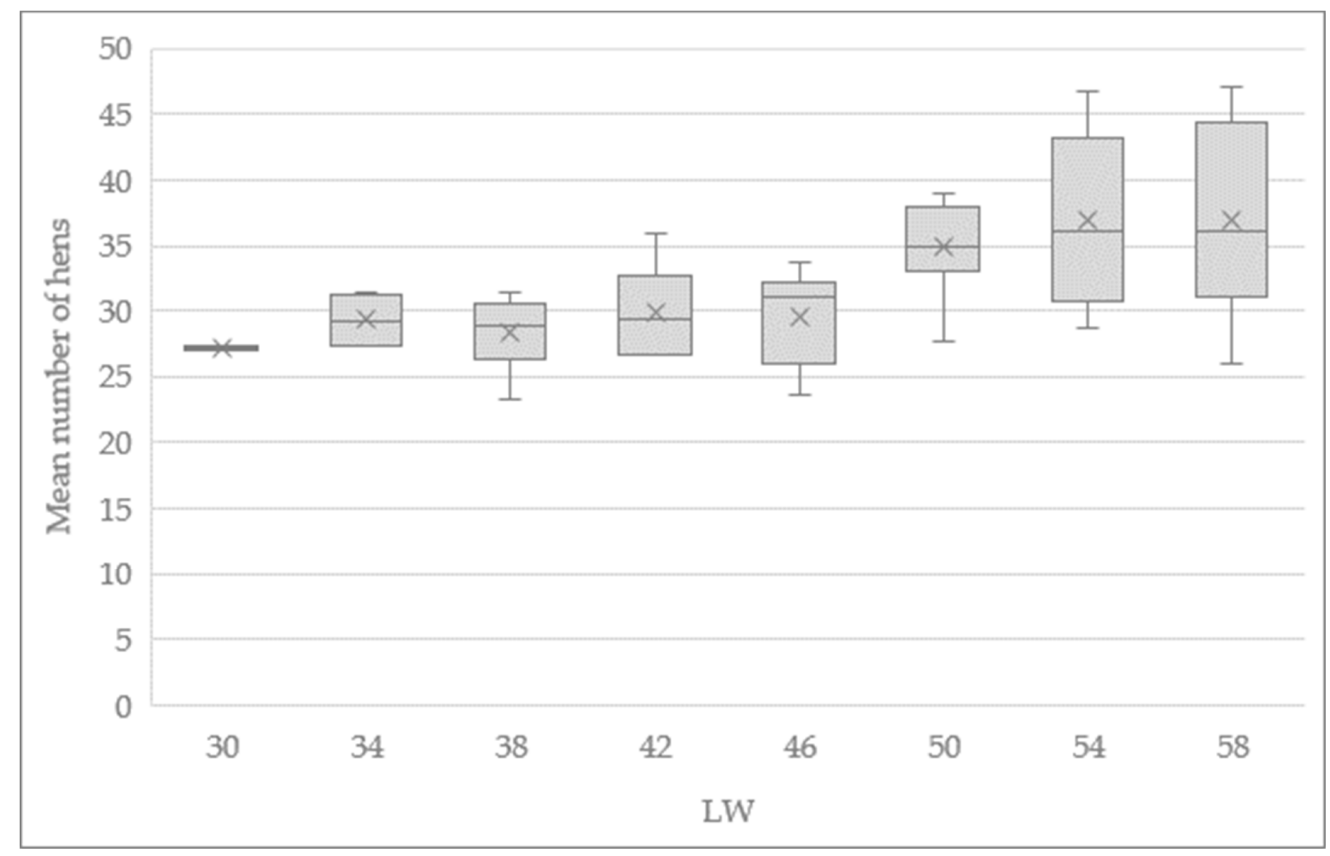

Figure 4. Mean number of hens in the observation areas beneath the device (ScA 1 and ScA 3) during the examined times of maize supply for birds of different ages ( $\mathrm{LW}: \mathrm{F}=3.75 ; p<0.01$ ). Boxplots indicate the data range, median, lower, and upper quartiles, and mean value.

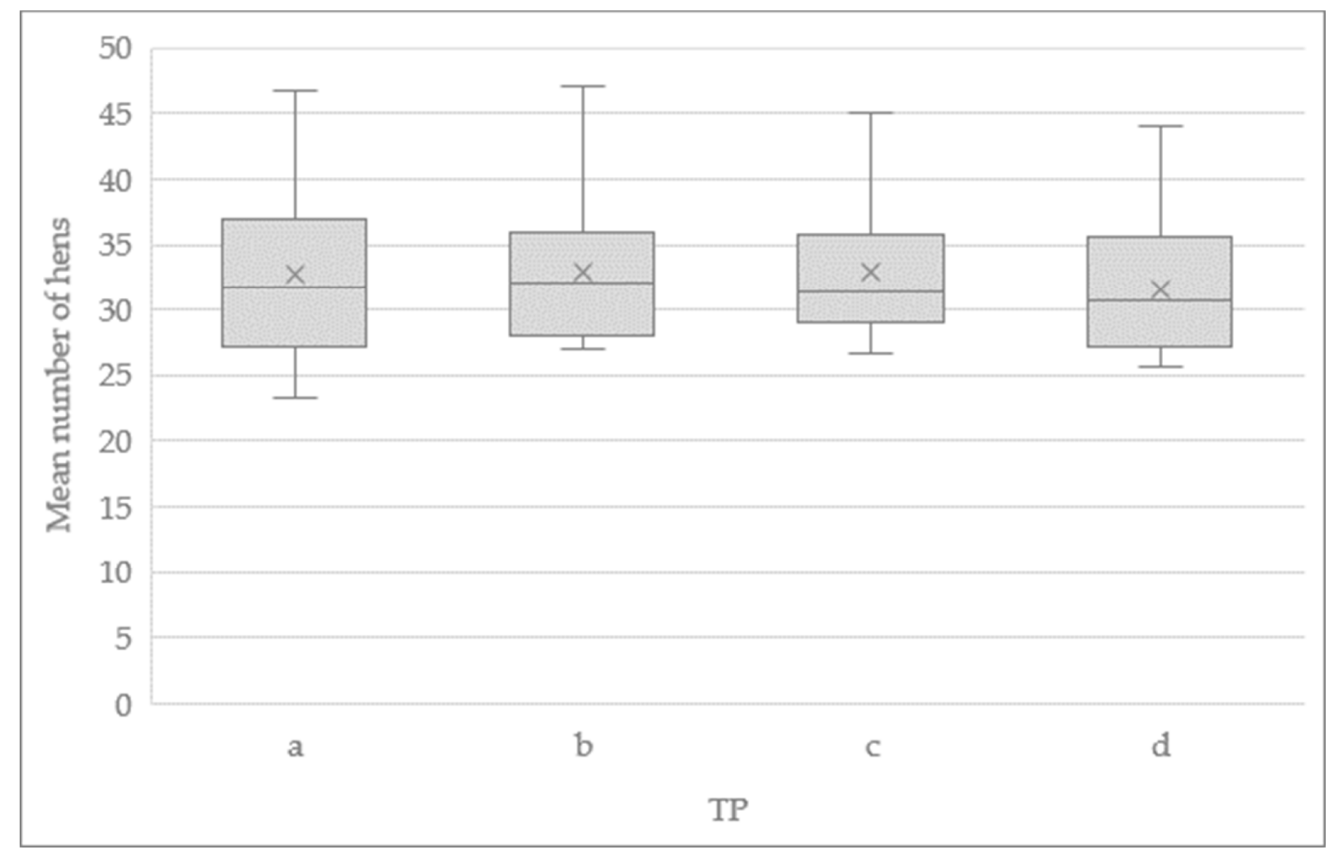

Figure 5. Mean number of hens in the observation areas beneath the device (ScA 1 and ScA 3) during the examined times (TP a-d) of maize supply for birds ranging in age from 30 to 58 weeks (TP: $\mathrm{F}=0.23$; $p=0.88)$. Boxplots indicate the data range, median, lower, and upper quartiles, and mean value. 
The material $(\mathrm{M})$ revealed a significant effect as well $(\mathrm{M}: \mathrm{F}=27.46 ; p<0.01)$. More hens were found after the addition of grains (bg) (Figure 6).

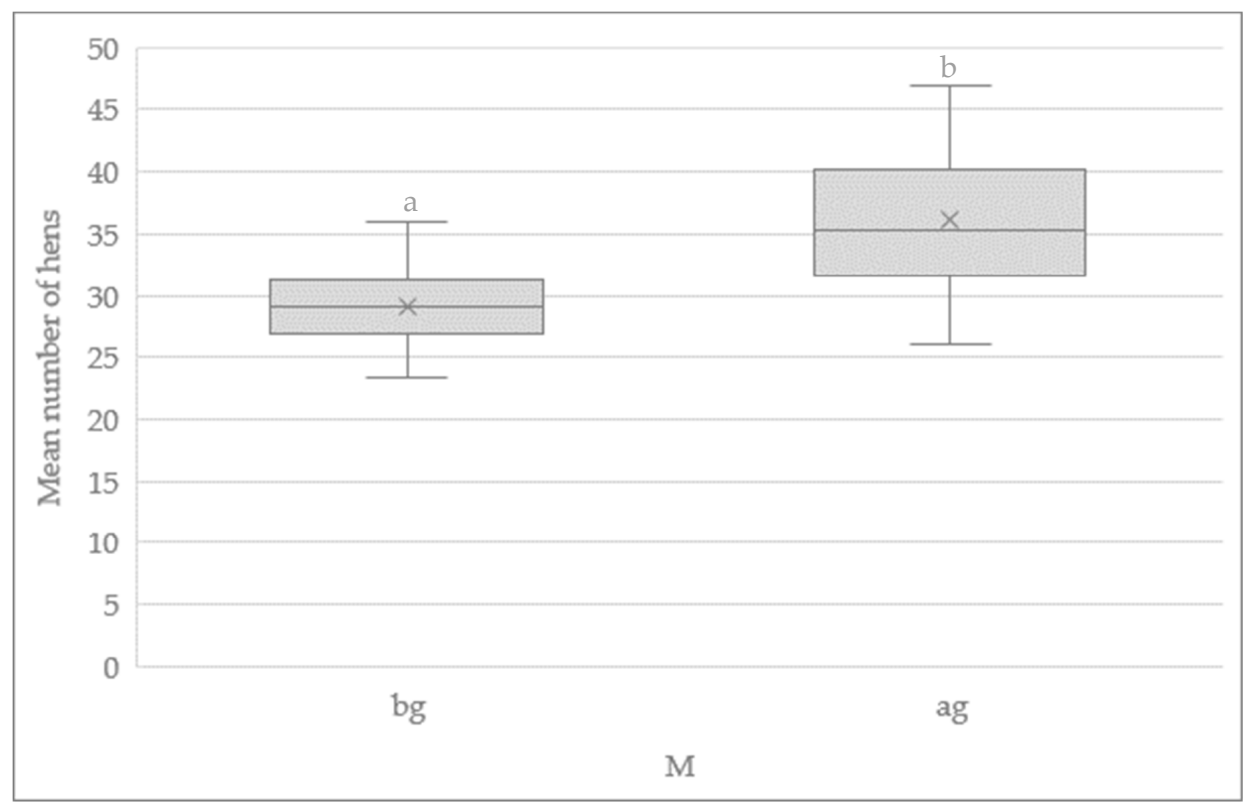

Figure 6. Mean number of hens in the observation areas beneath the device (ScA 1 and ScA 3) during the examined times of maize supply before $(\mathrm{M} \mathrm{bg})$ and after $(\mathrm{M}$ ag) grain addition $(\mathrm{M}: \mathrm{F}=27.46$; $p<0.01)$. Different superscripts indicate significant differences $(p<0.05)$. Boxplots indicate the data range, median, lower, and upper quartiles, and mean value.

\subsection{Plumage Condition}

The development of FL and ID for selected body sections over the entire observational period is shown in Figures 7 and 8 ( $a$ and $b$ ). At the beginning of the observations (i.e., when the birds were 21 weeks of age), no FL and only minor ID (score 1; 16\% within head/neck) were found. However, plumage condition and integument deteriorated with increasing age.

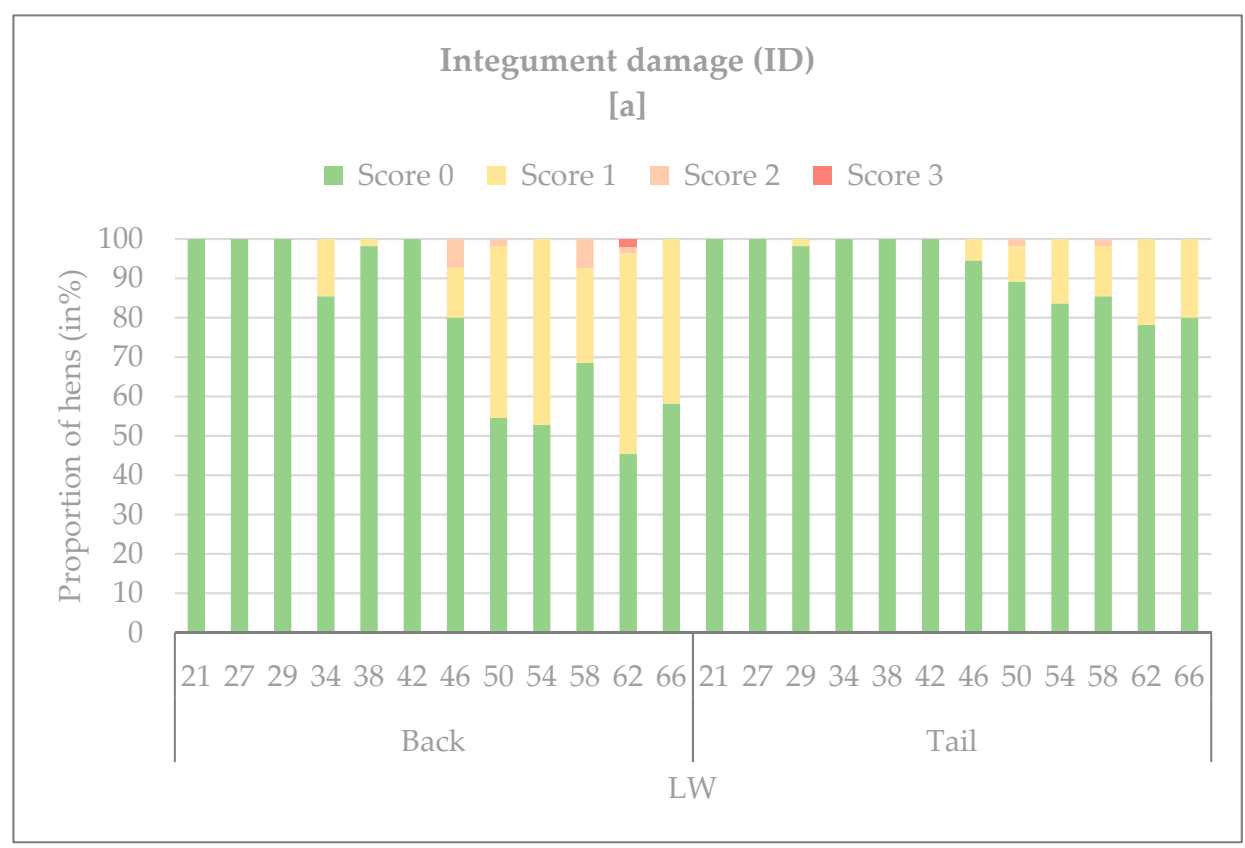

Figure 7. Cont. 


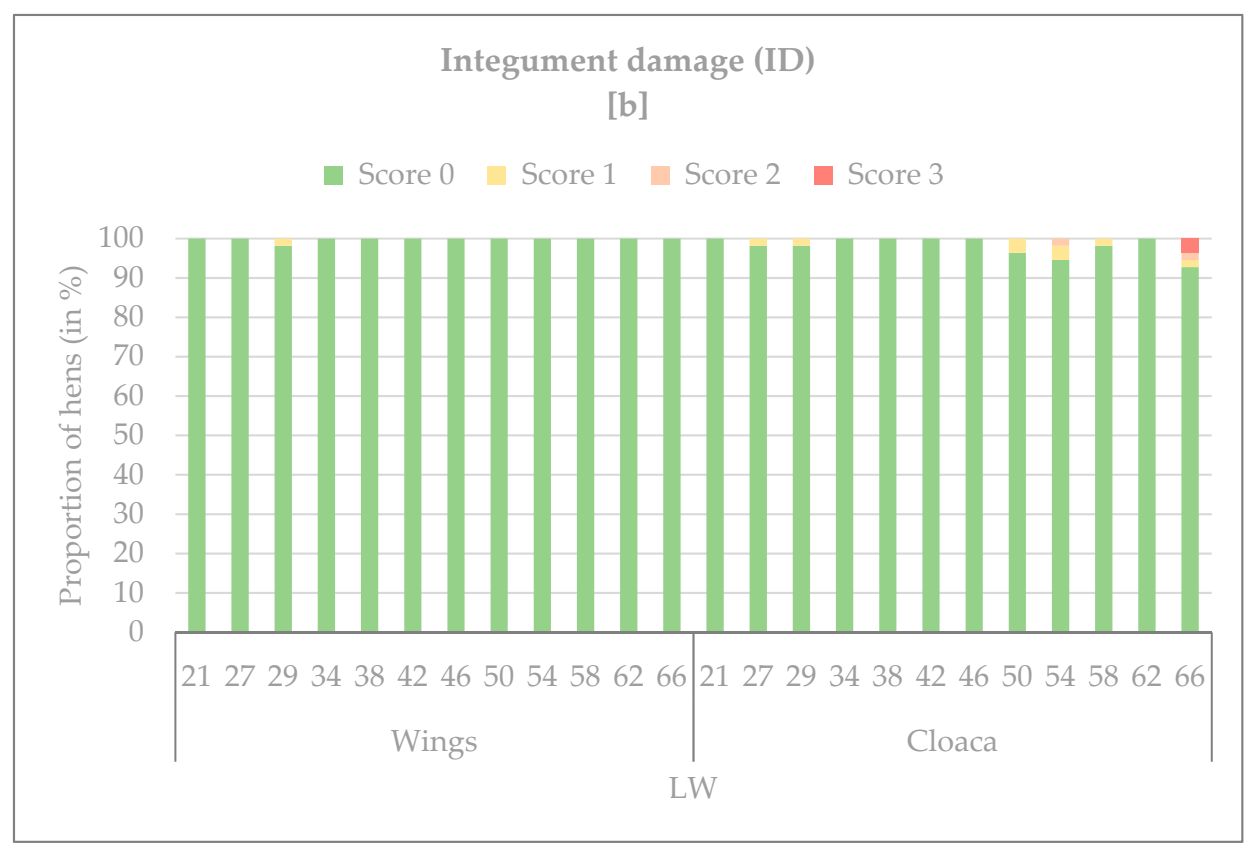

Figure 7. (a) and (b) Proportion (in \%) of hens ( $n=50$ (week 21); $n=55$ (weeks 27-66)) with different scores (0-3) for ID at different ages (LW) for different body sections (a: back and tail; b: wings and cloaca).

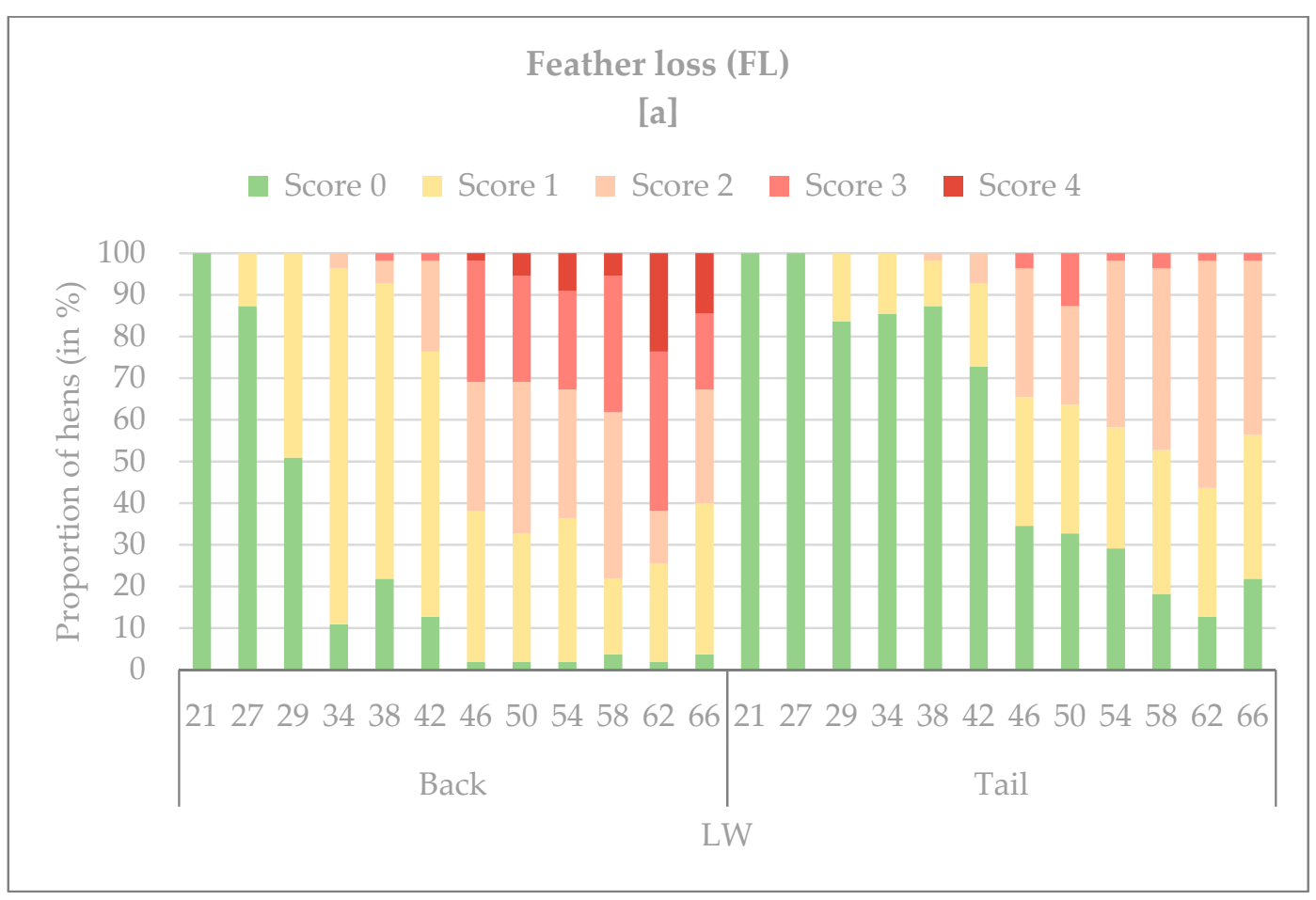

Figure 8. Cont. 


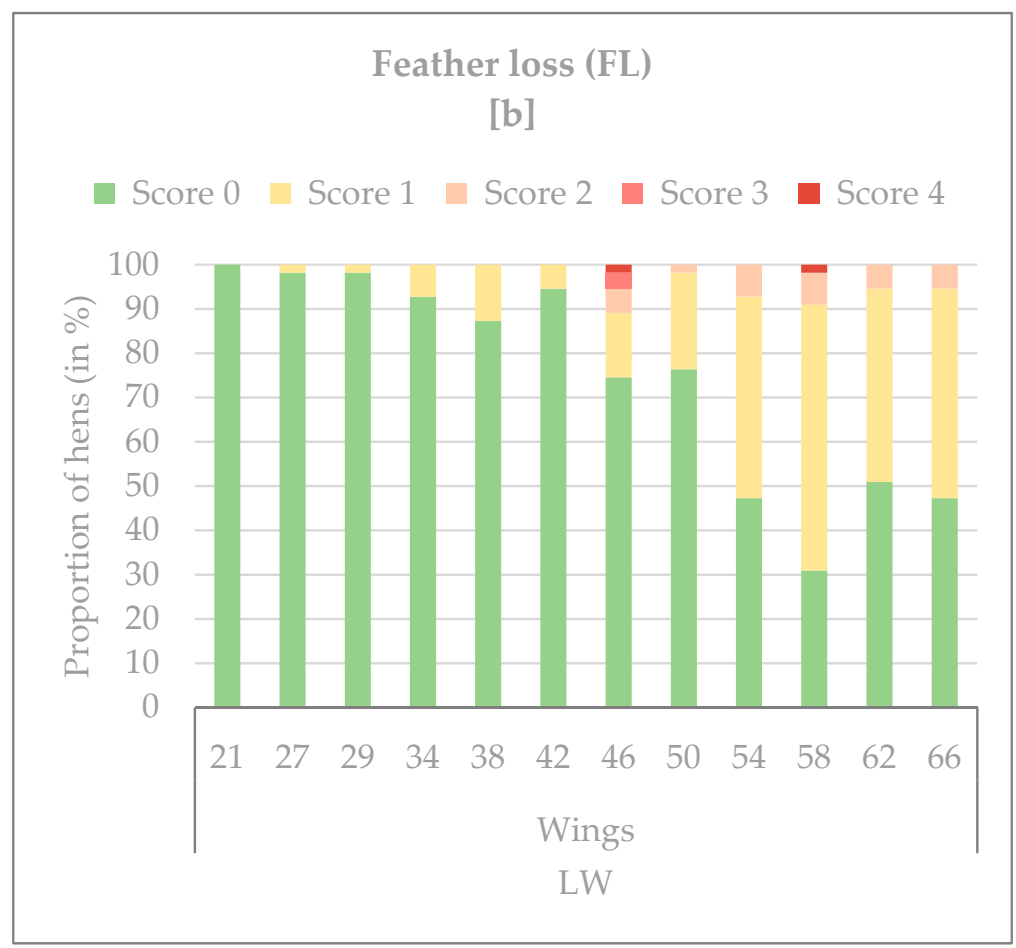

Figure 8. (a) and (b) Proportion (in \%) of hens ( $n=50$ (week 21); $n=55$ (weeks 27-66)) with different scores (0-4) for FL at different LW for different body sections (a: back and tail; b: wings).

\subsubsection{Integument Damage}

Integument damage was observed for each body section in varying degrees. Wings were affected only slightly, and minor ID (score 1) was found in one of the 55 observed hens (1.8\%) at an age of 29 weeks. Within that body part, moderate (score 2) or severe (score 3) ID was never noted. Despite that, minor lesions on the head/neck occurred throughout the entire observational period with increasing frequency (i.e., $16.0 \%$ at 21 weeks of age and $81.8 \%$ at 66 weeks of age). Later during the laying period, an increasing percentage of hens exhibited minor ID on their backs, breasts/bellies, and tails. At an age of 66 weeks, $41.8 \%$ (back and breast/belly) and 20.0\% (tail) of hens were determined to have an ID score of 1.

Moderate lesions occasionally appeared in a few hens on the cloaca, back, breast/belly, and tail, and were most frequently noted on the cloaca $(3.6 \%$ at weeks 54,62 , and 66$)$ and back $(7.4 \%$ at week 58). Furthermore, only the hens' cloaca (3.6\% at week 66$)$ and back (1.8\% at week 62$)$ were affected by severe ID at the end of the observational period.

\subsubsection{Feather Loss}

The first FL was noted within all the observed body sections, except for the tail, when the hens were 27 weeks old. Within that age, a small number of hens exhibited slight FL (score 1) on their back $(12.7 \%)$, head/neck $(3.6 \%)$, and wings $(1.8 \%)$, but a considerably higher proportion $(72.7 \%)$ of the hens' breasts/bellies was affected by the same score. Furthermore, a FL score of $2(14.5 \%)$ or $3(1.8 \%)$ first occurred within breast/belly at that age. At an age of 66 weeks, $47.2 \%$ of the birds exhibited minor FL on their wings and moderate loss (score 2 ) was noted only on a few hens (5.4\%). Deterioration was most severe on the back and breast/belly. Severe FL (scores of 3 or 4 ) was detected in $32.7 \%$ of the hens on their backs and $76.3 \%$ of the hens on their breasts/bellies at an age of 66 weeks. Tail FL mainly remained moderate ( $41.8 \%$ with an age of 66 weeks), and only a minor number of hens exhibited more severe loss (FL score of 3 for $1.8 \%$ at an age of 66 weeks). 


\section{Discussion}

Automatic enrichment devices are an innovative idea to support farmers in offering enrichment material within laying hen flocks, and thereby improve animal welfare. Giersberg et al. [43] showed that the attractiveness of winter gardens increased due to automatically offered moistened maize silage. The present case study was a follow-on investigation of the use of such techniques under on-farm conditions because acceptance may vary among flocks, farms, and management strategies.

One aim of this investigation was to reveal whether there might be a relationship between the number of hens residing in the scratching area inside a stable and the provision of enrichment material by an automatic device to get an impression of the device's usage. On the one hand, significantly more hens were noted within the scratching areas beneath the device (ScA 1 and ScA 3) during the afternoon hours (DT 1), when material was offered up to five times, compared with earlier in the day when the device was not running (DT 2). Furthermore, significantly more hens were noted beneath the device (ScA 1 and ScA 3) than in the control area without the device (ScA 2) at all the observed times of maize supply (TP a-d). Otherwise, there was no significant difference in the number of hens residing in the control area (ScA 2) in the hours before and hours during the provision of maize silage (DT 1 and DT 2). In conclusion, automatically offering dried maize silage (with partially added wheat and oats) appears to attract hens' attention and resulted in an increase in the number of hens located in the scratching areas beneath the device.

Although these findings are consistent with the results of Giersberg et al. [43], diurnal behavior patterns or general differences in space use might have influenced our findings. Littered areas are known to be used preferably in the afternoon $[2,45,46]$, which may be an explanation for the increased number of hens within the observed areas beneath the device (ScA 1 and ScA 3) during the hours of maize supply (DT 2). However, as the interaction between DT and scratching areas revealed a significant effect in our study, the results presented here rather indicate the difference being due to the presence of the device. Still, Channing et al. [46] noted an uneven distribution of hens over pens and variations in hen density within specific areas of pens (i.e., nine to 41 birds per square meter). Additionally, Campbell et al. [45] found that perches situated between enclosures and littered areas functioned as a transition zone: hens used them to switch between these different areas. The control area (ScA 2) was located in the corridor with pop holes leading to the winter garden (i.e., a free-range area), as this corridor was the only one in the stable without a technical device (Figure 1). Therefore, the overall small number of hens that resided could have been a sign of a less pronounced and transitional usage of this corridor.

Giersberg et al. [43] also determined the usage of automatically offered material by hens in their $73^{\text {rd }}$ to $77^{\text {th }}$ weeks of life. These authors counted hens foraging in a circular formation around the center of trickled material directly after its provision. We also noted the circular formations of hens beneath the device after maize supply. However, in our study, it was not possible to adapt that method because of different spatial conditions of corridors within the stable compared with the winter gardens, as analyzed by Giersberg et al. [43]. These circular formations extended to the areas below the aviary systems, which also served as scratching areas. For this reason, the total expand of the formations could not be visualized using the camera traps, because they were partly hidden through the aviaries. Nevertheless, circular formations were noted within the analyzed pictures, which supports the assumption that the automatic device increased the number of hens in the scratching areas. Therefore, the number of hens residing in the defined areas beneath the device during times of supply can serve as an indicator for the usage of the device.

Furthermore, some factors of special interest to farmers might have influenced the usage of the device. Farmers of free-range housing systems have reported that their hens are more strongly attracted to stable sections near the packing station (i.e., at the front of the stable). Although the stables are sectioned into units containing a maximum of 6000 hens for legal requirements (TierSchNutztV, German law), hens can move between these sections via the free-range area. For this reason, some differences in the number of hens in the two areas beneath the device (ScA 1 and ScA 3) could be expected: ScA 1 
was situated in the front of the stable, and ScA 3 was situated in the back. However, the mean number of hens did not differ significantly. It was not possible to evaluate whether hens preferably resided in the front section of the stable, but the device might support an even distribution of the hens over the stable in free-range systems due to changes in the relative attractiveness of different areas.

A main interest of farmers is not disturbing egg laying during morning hours. Further on, feather pecking and cannibalism have been reported to be linked to foraging and dustbathing behavior, and therefore to appear mainly in the afternoon [19,47-49]. The provision of maize silage during the afternoon seemed to be reasonable, and the device first ran at 13:50 (seven hours and 50 minutes after lights switched on). Different times of maize supply in the afternoon were not shown to affect the usage of the device. However, it might be interesting to investigate whether a more frequent supply of maize is associated with a decrease in attractiveness, and whether there is an optimum application frequency.

The birds' age was found to have an influence on the number of hens beneath the device during times of maize supply as well as the addition of grain. However, as both factors are mutually dependent, the results of the presented study cannot predict with certainty which factor is decisive. Grains were provided as a reaction to the occurrence of feather pecking behavior in this study; therefore, an increase in the number of hens using the device might be due an increase in the general need to peck (or to forage). Further investigations using different materials provided by the device might help obtain a better insight here. Investigations into the influence of bird age on the usage of pen areas, range areas, and littered areas have yielded different results. Two studies revealed no effect, either within a littered area inside a stable [2] or within a free-range area [50]. However, another study showed that the number of hens on the floor areas of a perchery house increased with bird age [46]. However, the design of these studies differed, which makes it difficult to compare their findings. For the case of development of feather pecking and cannibalism in laying hen flocks, recommendation leaflets/guiding lines for farmers propose emergency plans [41,51]. Besides other management treatments, they suggest to increase the provision of enrichment material. Adding grain to the ratio of maize silage from the 47th week of age and onwards might have improved the interaction of the hens with the maize silage. However, as stated above, further research is necessary to prove these results. If a larger number of hens over time are affected by the addition of grain, an enrichment device might function as support for dealing with an outbreak of feather pecking and cannibalism in a flock.

Given a closer look at the development of plumage and integument condition in the observed laying hen flock, integument damage (ID) was mostly slight, but feather loss (FL) developed more severely until the end of the observation period. When interpreting the results of the scoring, some factors should be considered. Alterations on some body parts may be caused by factors other than feather pecking or cannibalism that were not determined within the scoring system $[8,41]$. Stress-induced molting or aggressive pecking can also lead to FL on the head/neck, which is not associated with feather pecking or cannibalism. In addition, injuries to the head, comb, or wattle might originate from aggressive pecking, which occurs due to clarification of the pecking order within a group of hens, and not because of cannibalism. Furthermore, brood patches cause FL on the breast. Therefore, it seems reasonable to draw conclusions about the occurrence of feather pecking and cannibalism behavior after excluding analyses of the head/neck and breast/belly.

Lesions on the birds' wings and tails were either slight or, in case of moderate lesions on the tail, only occurred in a few hens. Integument damage on the back was mainly slight to moderate, and ongoing severe lesions were not noted. Even though the proportion of hens exhibiting cloacal lesions was not high, the more severe lesions that were noted during the birds' $66^{\text {th }}$ week of life could be the first signs of vent pecking. Nevertheless, there was no indication of cannibalism in general until that age.

Unlike ID, feather condition had already declined at the beginning of the laying period, and deterioration proceeded more quickly and intensely, leading to feather-pecking behavior. Between visits in weeks 42-46, there was an increase in severe FL (i.e., score 3) on the birds' backs. The proportion of birds exhibiting this condition increased from $1.82 \%$ to $29.09 \%$. Score 3 loss also 
occurred within that age for the first time on the birds' wings and tails. Whereas severe loss (i.e., scores 3 and 4) seemed to be a single phenomenon for the tails and wings, severe loss on the birds' backs deteriorated in a more constant fashion.

Since feather pecking can be caused by multiple factors, it is difficult to draw conclusions on the exact reasons for its occurrence within the observed flock. The interruption of the provision of potatoes might have been a factor, or potential problems with wet areas, or the birds' confinement at the beginning of the laying period. Many studies have also determined the strong influence of rearing factors on this disorder $[16,18,19,21]$. Proving all the possible considerations is beyond the scope of this study. Offering grain in addition to maize silage via the device was an idea to stop the deterioration. Whether feather pecking would have been worse without this addition of grain could not be assessed in this study due to the lack of a control group. To evaluate such relations, setups that are more experimental can provide new insights.

\section{Conclusions}

The study demonstrated that enrichment material offered by an automatic device attracted hens' attention. Therefore, this enrichment device seems to be a useful tool to offer enrichment material in laying hen husbandries and to realize a comprehensive supply of material for a large number of hens of a flock within a stable. Although this on-farm study examined various important factors connected to the usage of automatic enrichment devices, additional—and at least more experimental-investigations are required to better understand all the possible interrelations amongst its usage and between the usage and hens' condition.

Author Contributions: Conceptualization, B.S.; Methodology, M.S. and K.K.; Validation, J.S., K.K. and B.S.; Formal Analysis, M.S.; Investigation, M.S.; Data Curation, J.S.; Writing-Original Draft Preparation, M.S.; Writing-Review and Editing, N.K.; Supervision, N.K. and B.S.; Project Administration, K.K.; Funding Acquisition, N.K. and B.S.

Funding: The EIP-AGRI-project Poultry Activity Farm (PAF) was funded through the European Agricultural Fund for Rural Development (EAFRD).

Acknowledgments: The authors are grateful for the support of the farmer.

Conflicts of Interest: The authors declare no conflict of interest. The funders had no role in the design of the study; in the collection, analyses, or interpretation of data; in the writing of the manuscript, or in the decision to publish the results.

Ethical Statement: All of the animals were housed in accordance with EU (European Directive 2008/120/EC) and national law (Tierschutzgesetz, Tierschutz-Nutztierhaltungs-Verordnung). In compliance with European Directive 2010/63/EC Article 15. (f), the present study did not imply any invasive procedure or treatment to the animals.

\section{References}

1. Sherwin, C.M.; Richards, G.J.; Nicol, C.J. Comparison of the Welfare of Layer Hens in 4 Housing Systems in the UK. Br. Poult. Sci. 2010, 51, 488-499. [CrossRef] [PubMed]

2. Odén, K.; Keeling, L.J.; Algers, B. Behaviour of Laying Hens in Two Types of Aviary Systems on 25 Commercial Farms in Sweden. Br. Poult. Sci. 2002, 43, 169-181. [CrossRef] [PubMed]

3. Niebuhr, K.; Zaludik, K.; Gruber, B.; Thenmaier, I.; Lugmair, A.; Baumung, R.; Troxler, J. Untersuchungen Zum Auftreten von Kannibalismus Und Federpicken in Alternativen Legehennenhaltungen in Österreich-Empfehlungen Für Die Praxis. Ländlicher Raum 2006, 2006, 1-21.

4. Hegelund, L.; Sørensen, J.T.; Hermansen, J.E. Welfare and Productivity of Laying Hens in Commercial Organic Egg Production Systems in Denmark. NJAS Wageningen J. Life Sci. 2006, 54, 147-155. [CrossRef]

5. Bestman, M.; Wagenaar, J.-P. Health and Welfare in Dutch Organic Laying Hens. Animals 2014, 4, 374-390. [CrossRef] [PubMed]

6. Tauson, R.; Svensson, S.A. Influence of Plumage Conditions on the Hen's Feed Requirment. Swed. J. Agric. Res. 1980, 10, 35-39.

7. Emmans, G.C.; Charles, D.R. Climatic Environment and Poultry Feeding in Practice. In Nutrition and Climatic Environment; Haresign, W., Swan, H., Lewis, D., Eds.; Butterworth: London, UK, 1977; pp. 31-49. 
8. Savory, C.J. Feather Pecking and Cannibalism; Elsevier Ltd.: Amsterdam, The Netherlands, 1995; Volume 51. [CrossRef]

9. Gentle, M.J.; Hunter, L.N. Physiological and Behavioural Responses Associated with Feather Removal in Gallus Gallus Var Domesticus. Res. Vet. Sci. 1991, 50, 95-101. [CrossRef]

10. Fossum, O.; Jansson, D.S.; Etterlin, P.E.; Vågsholm, I. Causes of Mortality in Laying Hens in Different Housing Systems in 2001 to 2004. Acta Vet. Scand. 2009, 51, 3. [CrossRef]

11. El-Lethey, H.; Aerni, V.; Jungi, T.W.; Wechsler, B. Stress and Feather Pecking in Laying Hens in Relation to Housing Conditions. Br. Poult. Sci. 2000, 41, 22-28. [CrossRef]

12. Marchant-Forde, R.M.; Fahey, A.G.; Cheng, H.W. Comparative Effects of Infrared and One-Third Hot-Blade Trimming on Beak Topography, Behavior, and Growth. Poult. Sci. 2008, 87, 1474-1483. [CrossRef]

13. Jongman, E.C.; Glatz, P.C.; Barnett, J.L. Changes in Behaviour of Laying Hens Following Beak Trimming at Hatch and Re-Trimming at 14 Weeks. Asian-Australas. J. Anim. Sci. 2008, 21, 291-298. [CrossRef]

14. Hughes, B.O.; Gentle, M.J. Beak Trimming of Poultry: Its Implications for Welfare. Worlds. Poult. Sci. J. 1995, 51, 51-61. [CrossRef]

15. Gentle, M.J.; Hughes, B.O.; Fox, A.; Waddington, D. Behavioural and Anatomical Consequences of Two Beak Trimming Methods in 1- and 10-d-old Domestic Chicks. Br. Poult. Sci. 1997, 38, 453-463. [CrossRef] [PubMed]

16. Janczak, A.M.; Riber, A.B. Review of Rearing-Related Factors Affecting the Welfare of Laying Hens. Poult. Sci. 2015, 94, 1454-1469. [CrossRef] [PubMed]

17. Dixon, L.M. Feather Pecking Behaviour and Associated Welfare Issues in Laying Hens. Avian Biol. Res. 2008, 1, 73-87. [CrossRef]

18. Keppler, C. Untersuchungen Wichtiger Einflussfaktoren Auf Das Auftreten von Federpicken Und Kannibalismus Bei Unkupierten Legehennen in Boden- Und Volierenhaltungen Mit Tageslicht Unter Besonderer Berücksichtigung Der Aufzuchtphase; Kassel University Press: Kassel, Germany, 2010.

19. Rodenburg, T.B.; van Krimpen, M.M.; de Jong, I.C.; de Haas, E.N.; Kops, M.S.; Riedstra, B.J.; Nordquist, R.E.; Wagenaar, J.P.; Bestman, M.; Nicol, C.J. The Prevention and Control of Feather Pecking in Laying Hens: Identifying the Underlying Principles. Worlds. Poult. Sci. J. 2013, 69, 361-374. [CrossRef]

20. Kjaer, J.B.; Bessei, W. The Interrelationships of Nutrition and Feather Pecking in the Domestic Fowl-A Review. Arch. für Geflügelkd. 2013, 77, 1-9.

21. Spindler, B.; Giersberg, M.F.; Andersson, R.; Kemper, N. Legehennenhaltung Mit Intaktem Schnabel-Übersichtsbericht Zum Aktuellen Stand Aus Praktisch-Wissenschaftlicher Sicht. Züchtungskunde 2016, 6, 475-493.

22. Bolhuis, J.E.; Rodenburg, T.B.; Groothuis, T.G.G.; de Haas, E.N.; Kemp, B. Parents and Early Life Environment Affect Behavioral Development of Laying Hen Chickens. PLoS ONE 2014, 9, e90577. [CrossRef]

23. De Haas, E.N.; Bolhuis, J.E.; de Jong, I.C.; Kemp, B.; Janczak, A.M.; Rodenburg, T.B. Predicting Feather Damage in Laying Hens during the Laying Period. Is It the Past or Is It the Present? Appl. Anim. Behav. Sci. 2014, 160, 75-85. [CrossRef]

24. Bestman, M.; Koene, P.; Wagenaar, J.-P. Influence of Farm Factors on the Occurrence of Feather Pecking in Organic Reared Hens and Their Predictability for Feather Pecking in the Laying Period. Appl. Anim. Behav. Sci. 2009, 121, 120-125. [CrossRef]

25. Nicol, C.J.; Lindberg, A.C.; Phillips, A.J.; Pope, S.J.; Wilkins, L.J.; Green, L.E. Influence of Prior Exposure to Wood Shavings on Feather Pecking, Dustbathing and Foraging in Adult Laying Hens. Appl. Anim. Behav. Sci. 2001, 73, 141-155. [CrossRef]

26. De Jong, I.C.; Gunnink, H.; Rommers, J.M.; Bracke, M.B.M. Effect of Substrate during Early Rearing on Floorand Feather Pecking Behaviour in Young and Adult Laying Hens. Einfluss des einstreusubstrats der frühen aufzuchtphase auf das boden- und federpicken bei jungen und adulten legehennen 2013, 77, 15-22.

27. Zepp, M.; Louton, H.; Erhard, M.; Schmidt, P.; Helmer, F.; Schwarzer, A. The Influence of Stocking Density and Enrichment on the Occurrence of Feather Pecking and Aggressive Pecking Behavior in Laying Hen Chicks. J. Vet. Behav. 2018, 24, 9-18. [CrossRef]

28. Steenfeldt, S.; Kjaer, J.B.; Engberg, R.M. Effect of Feeding Silages or Carrots as Supplements to Laying Hens on Production Performance, Nutrient Digestibility, Gut Structure, Gut Microflora and Feather Pecking Behaviour. Br. Poult. Sci. 2007, 48, 454-468. [CrossRef] [PubMed] 
29. McAdie, T.M.; Keeling, L.J.; Blokhuis, H.J.; Jones, R.B. Reduction in Feather Pecking and Improvement of Feather Condition with the Presentation of a String Device to Chickens. Appl. Anim. Behav. Sci. 2005, 93, 67-80. [CrossRef]

30. Mason, G.J.; Dixon, L.M.; Duncan, I.J.H. The Effects of Four Types of Enrichment on Feather Pecking Behaviour in Laying Hens Housed in Barren Environments. Anim. Welf. 2010, 19, 429-435.

31. Daigle, C.L.; Rodenburg, T.B.; Bolhuis, J.E.; Swanson, J.C.; Siegford, J.M. Use of Dynamic and Rewarding Environmental Enrichment to Alleviate Feather Pecking in Non-Cage Laying Hens. Appl. Anim. Behav. Sci. 2014, 161, 75-85. [CrossRef]

32. Blokhuis, H.J.; Van der Haar, J.W. Effects of Pecking Incentives during Rearing on Feather Pecking of Laying Hens. Br. Poult. Sci. 1992, 33, 17-24. [CrossRef] [PubMed]

33. Aerni, V.; El-Lethey, H.; Wechsler, B. Effect of Foraging Material and Food Form on Feather Pecking in Laying Hens. Br. Poult. Sci. 2000, 41, 16-21. [CrossRef]

34. De Koning, C.; Kitessa, S.M.; Barekatain, R.; Drake, K. Determination of Range Enrichment for Improved Hen Welfare on Commercial Fixed-Range Free-Range Layer Farms. Anim. Prod. Sci. 2018. [CrossRef]

35. Dawkins, M.S. Time Budgets in Red Junglefowl as a Baseline for the Assessment of Welfare in Domestic Fowl. Appl. Anim. Behav. Sci. 1989, 24, 77-80. [CrossRef]

36. Bubier, N.E. The Behavioural Priorities of Laying Hens: The Effects of Two Methods of Environment Enrichment on Time Budgets. Behav. Processes 1996, 37, 239-249. [CrossRef]

37. Hughes, B.O.; Duncan, I.J.H. The Notion of Ethological 'Need', Models of Motivation and Animal Welfare. Anim. Behav. 1988, 36, 1696-1707. [CrossRef]

38. Dawkins, M.S. From an Animal's Point of View: Motivation, Fitness, and Animal Welfare. Behav. Brain Sci. 1990, 13, 1-9. [CrossRef]

39. Mellor, D.J. Moving beyond the "Five Freedoms" by Updating the "Five Provisions" and Introducing Aligned “Animal Welfare Aims". Animals 2016, 6, 59. [CrossRef] [PubMed]

40. Jung, L.; Knierim, U. Are Practice Recommendations for the Prevention of Feather Pecking in Laying Hens in Non-Cage Systems in Line with the Results of Experimental and Epidemiological Studies? Appl. Anim. Behav. Sci. 2018, 200, 1-12. [CrossRef]

41. Keppler, C.; Fetscher, S.; Hilmes, N.; Knierim, U. Basiswissen MTool Eine Managementhilfe Für Legehennenaufzucht Und -Haltung. 2017. Available online: www.mud-tierschutz.de (accessed on 28 April 2019).

42. Minimierung von Federpicken und Kannibalismus bei Legehennen mit intaktem Schnabel; Landwirtschaftskammer Niedersachsen (BMEL, BEL): Berlin, Germany, 2016.

43. Giersberg, M.F.; Kemper, N.; Spindler, B. On-Farm Evaluation of an Automatic Enrichment Device with Maize Silage for Laying Hens. J. Appl. Anim. Welf. Sci. 2018, 1-11. [CrossRef]

44. Giersberg, M.; Spindler, B.; Kemper, N. Assessment of Plumage and Integument Condition in Dual-Purpose Breeds and Conventional Layers. Animals 2017, 7, 97. [CrossRef]

45. Campbell, D.L.M.; Makagon, M.M.; Swanson, J.C.; Siegford, J.M. Laying Hen Movement in a Commercial Aviary: Enclosure to Floor and Back Again. Poult. Sci. 2016, 95, 176-187. [CrossRef]

46. Channing, C.E.; Hughes, B.O.; Walker, A.W. Spatial Distribution and Behaviour of Laying Hens Housed in an Alternative System. Appl. Anim. Behav. Sci. 2001, 72, 335-345. [CrossRef]

47. Kjaer, J. Diurnal Rhythm of Feather Pecking Behaviour and Condition of Integument in Four Strains of Loose Housed Laying Hens. Appl. Anim. Behav. Sci. 2000, 65, 331-347. [CrossRef]

48. Blokhuis, H.J.; Wiepkema, P.R. Studies of Feather Pecking in Poultry. Vet. Q. 1998, 20, 6-9. [CrossRef]

49. Savory, C.J. Diurnal Feeding Patterns in Domestic Fowls: A Review. Appl. Anim. Ethol. 1980, 6, 71-82. [CrossRef]

50. Rodriguez-Aurrekoetxea, A.; Estevez, I. Use of Space and Its Impact on the Welfare of Laying Hens in a Commercial Free-Range System. Poult. Sci. 2016, 95, 2503-2513. [CrossRef] [PubMed]

51. Empfehlungen zur Verhinderung von Federpicken und Kannibalismus bei Jung und Legehennen; Niedersächsisches Ministerium für Ernährung Landwirtschaft und Verbraucherschutz: Hanover, Germany, 2017.

(C) 2019 by the authors. Licensee MDPI, Basel, Switzerland. This article is an open access article distributed under the terms and conditions of the Creative Commons Attribution (CC BY) license (http://creativecommons.org/licenses/by/4.0/). 